\title{
Feasibility of purely laparoscopic resection of locally advanced rectal cancer in obese patients
}

\author{
Tolutope Oyasiji ${ }^{12}$, Keith Baldwin', Steven C Katz ${ }^{1}$, N Joseph Espat ${ }^{1}$ and Ponnandai Somasundar ${ }^{* *}$
}

\begin{abstract}
Background: Totally laparoscopic (without hand-assist) resection for rectal cancer continues to evolve, and both obesity and locally advanced disease are perceived to add to the complexity of these procedures. There is a paucity of data on the impact of obesity on perioperative and oncologic outcomes for totally-laparoscopic rectal cancer resection (TLRR) for locally advanced disease.

Methods: In order to identify potential limitations of TLRR, a single-institution database was queried and identified 26 patients that underwent TLRR for locally advanced rectal cancers (T3/T4) over a three-year period. Patients were classified as normal-weight ( $\mathrm{NW}$, body mass index $(\mathrm{BMI})=18.5$ to $24.9 \mathrm{~kg} / \mathrm{m} 2)$, overweight $(\mathrm{OW}, \mathrm{BMl}=25$ to $29.9 \mathrm{~kg} / \mathrm{m} 2)$ and obese $(\mathrm{OB}, \mathrm{BMI}>/=30 \mathrm{~kg} / \mathrm{m} 2)$. Perioperative outcomes, lymph node harvest and margin status were assessed.
\end{abstract}

Results: Seven patients were classified as NW (26.9\%), 12 as OW (46.2\%) and 7 as OB (26.9\%). Age, tumor stage, gender and American Society of Anesthesiologists (ASA) scores were similar. OB had more co-morbidities (median 3.0, range 0.0 to 5.0 vs. 2.0, range 0.0 to 3.0 for NW and 1.0, range 0.0 to 3.0 for $\mathrm{OW}$ ). Five patients had tumors $<5 \mathrm{~cm}$ from anal verge ( $\mathrm{NW}=2 ; \mathrm{OW}=1 ; \mathrm{OB}=2$ ). A median of 19.0, range 9.0 to 32.0; 20.0, range 9.0 to 46.0 and 19.0, range 15.0 to 31.0 lymph nodes were retrieved in the NW, OW and OB, respectively (Not Significant (NS)). Median node ratios for NW, OW and $\mathrm{OB}$ were $0.32,0.13$ and 0.00 , respectively. All groups had negative proximal and distal margins. Radial margins were negative for $100 \%$ of NW, $83.3 \%$ of OW and $85.7 \%$ of OB (NS). Conversion rates were $14.3 \%$ for NW, $16.7 \%$ for OW \& $0 \%$ for OB (NS). NW, OW and OB had complication rates of $28.3 \%, 33.3 \%$ and $14.3 \%$, respectively. Median operative time, median estimated blood loss and median length of hospital stay were similar for all groups.

Conclusion: The perceived limitation that obesity would have on TLRR was not demonstrated by the analyzed data. Although our findings are limited by the modest sized cohort, the results suggest that it is reasonable to offer TLRR to obese patients with rectal cancer.

Keywords: Laparoscopic, Resection, Advanced, Rectal, Cancer, Obesity

\section{Background}

The introduction of laparoscopic rectal cancer surgery raised concerns about the feasibility, safety and oncologic adequacy of this modality. In recent years, the laparoscopic approach has come to be accepted as technically feasible and safe [1-4], with the TLRR gaining increasing acceptance.

The incidence of obesity is rising globally with $11 \%$ and $20 \%$ of the populations in France and the United States,

\footnotetext{
* Correspondence: psomasun@chartercare.org

'Division of Surgical Oncology, Department of Surgery, Roger Williams

Medical Center, Boston University, Prior 4, 825 Chalkstone Avenue,

Providence, RI 02908, USA

Full list of author information is available at the end of the article
}

respectively, reported as obese [1]. It is clear that the challenging situation of applying TLRR to obese patients is being encountered more frequently. In the recent past, the presence of locally advanced disease was considered a contraindication to TLRR. However, the modality is being increasingly used as locally advanced disease in obese patients is encountered more frequently [1].

Obese patients undergoing laparoscopic colorectal surgery present a technical challenge. Blood loss, duration of surgery and conversion rates have been reported to be greater for obese patients compared to the non-obese (1, 3 and 4). However, morbidity and mortality are comparable for both groups [1,3,4]. Adequacy of oncologic resections has also been verified in laparoscopic colon

\section{Biomed Central}


cancer resection [1,2]. However, both benign and malignant colonic conditions are included in most studies and few reports focus exclusively on laparoscopic colectomy for cancer [1,3-6]. In some cases colon and rectal cancers have been combined, and very few studies have evaluated the impact of obesity on TLRR [1,7]. Rather than compare outcomes of purely laparoscopic technique for rectal cancer resection between obese and non-obese patients, some series have mixed up cases of hand-assisted laparoscopic and purely laparoscopic techniques, in drawing comparison between the two groups. As such, there is insufficient broadly applicable data to guide the selection of obese patients for TLRR in the management of locally advanced rectal adenocarcinoma.

The goal of this study was to analyze the impact of obesity on perioperative outcomes for TLRR surgery done for locally advanced rectal cancer. We also assessed the lymph node retrieval and margin status of these operations as surrogates for oncologic adequacy.

\section{Methods}

Between July 2007 and March 2010, 26 patients with locally advanced rectal cancer (T3 or T4) underwent resection using TLRR. Preoperative staging included endorectal ultrasonography, thoracoabdominopelvic computerized tomographic scan or pelvic magnetic resonance imaging. After obtaining Institutional Review Board approval, a prospectively maintained database was queried for demographic, oncologic, perioperative, morbidity, mortality and pathologic data. Data collected included age, gender, body mass index (BMI), preoperative diagnosis, neoadjuvant therapy, distance to anal verge, co-morbidities, type of operation, ASA score, operative time, estimated blood loss, type of operation, intraoperative and postoperative complications, length of hospital stay, conversion rates, number of lymph nodes retrieved and margin status. Patients were categorized as normal weight (BMI 18.5 to $24.9 \mathrm{~kg} / \mathrm{m}^{2}$ ), overweight (BMI 25 to $29.9 \mathrm{~kg} / \mathrm{m}^{2}$ ) and obese (BMI $>/=$ $30 \mathrm{~kg} / \mathrm{m}^{2}$ ). NW, OW and OB were compared to identify potential differences in operating time, estimated blood loss, length of stay, complication, conversion, lymph node retrieval and margin status.

\section{Technique}

Four ports were routinely used, with placement in the left upper, right upper, right lower and suprapubic positions. Occasionally a fifth port in the left lower quadrant was inserted to facilitate retraction of the colon when a bulky mesentery was encountered, particularly in obese patients. Lesions were confirmed by rectal or proctoscopic examination, as well as preoperative tattooing. The medial to lateral approach was utilized for our dissection and mobilization. The inferior mesenteric artery
(IMA) was dissected and staple divided. The left ureter was identified, and the prescaral plane was carefully developed with preservation of the autonomic nerve fibers using the technique of sharp total mesorectal excision. The rectum was divided at least $3 \mathrm{~cm}$ distal to the tattoo using an articulating stapling device via the suprapubic port. The splenic flexure was mobilized as deemed necessary. A small 4 to $5 \mathrm{~cm}$ incision was then made for specimen extraction and proximal transection, and a circular stapler was used for all anastomoses.

\section{Results}

\section{Demographics}

Twenty-six total patients; 15 male (57.7\%) and 11 female (42.3\%) with T3 or T4 rectal cancers are reported in this series (Table 1). They were categorized into NW $(\mathrm{n}=7$ $(26.9 \%))$, OW $(\mathrm{n}=12(46.2 \%))$ and $\mathrm{OB}(\mathrm{n}=7(26.9 \%))$. The median ages $(\mathrm{NW}=65 \mathrm{yr}, \mathrm{OW}=63 \mathrm{yr}$, and $\mathrm{OB}=66 \mathrm{yr}$ ) were also similar (Table 1). The median BMIs for the three groups were $20.9 \mathrm{~kg} / \mathrm{m}^{2}$ (NW), $28.2 \mathrm{~kg} / \mathrm{m}^{2}(\mathrm{OW})$ and $36.1 \mathrm{~kg} / \mathrm{m}^{2}(\mathrm{OB})$.

Altogether, there were $22(84.6 \%)$ T3 tumors and 4 (15.4\%) T4 tumors. There was a comparable distribution of tumor stages across the three BMI groups (Table 2). A total of $77 \%$ of patients $(n=20)$ had rectal cancer while $23 \%(n=6)$ had rectosigmoid cancers. The rectosigmoid cancers were preoperatively and intraoperatively identified and treated as cancers in the upper third of the rectum. In the NW group, 57.1\% underwent neoadjuvant therapy; as opposed to $16.7 \%$ of OW patients and none of the OB patients. The presence of co-morbidities , including coronary artery disease, hypertension, diabetes mellitus, hyperlipidemia, chronic kidney disease, acute kidney disease, asthma, chronic obstructive pulmonary disease, hypothyroidism and hyperthyroidism, was documented for each patient. In terms of medical co-morbidities, NW patients had a median of $2.0 \mathrm{co}-$

Table 1 Demographics and other characteristics

\begin{tabular}{lccc}
\hline Characteristic & Normal weight & Overweight & Obese $\mathbf{N}=\mathbf{7}$ \\
\cline { 2 - 3 } & $\mathbf{N}=\mathbf{7}$ & $\mathbf{N}=\mathbf{1 2}$ & \\
\hline Sex & $5(71.4 \%)$ & $8(66.7 \%)$ & $2(28.6 \%)$ \\
Male; no (\%) & $2(28.6 \%)$ & $4(33.3 \%)$ & $5(71.4 \%)$ \\
Female; no (\%) & 65 & 63 & 66 \\
Median age (yr) & 52 to 85 & 46 to 86 & 52 to 76 \\
Range (yr) & 20.9 & 28.2 & 36.1 \\
Median BMl(kg/m $\left.{ }^{2}\right)$ & 18.8 to 24.9 & 25.5 to 29.8 & 31.1 to 41.5 \\
Range $\left(\mathrm{kg} / \mathrm{m}^{2}\right)$ & 2.0 & 1.0 & 3.0 \\
Median no. of comorbidities & 0.0 to 3.0 & 0.0 to 3.0 & 0.0 to 5.0 \\
Range & 2.0 & 2.0 & 3.0 \\
Median ASA score & 2.0 to 4.0 & 2.0 to 3.0 & 2.0 to 4.0 \\
Range & & &
\end{tabular}


Table 2 Tumor characteristics and distribution

\begin{tabular}{lccc}
\hline Characteristic & Normal weight & Overweight & Obese \\
\hline T stage & 6 & 9 & 7 \\
T3 & 1 & 3 & 0 \\
T4 & 4 & 2 & 0 \\
Neoadjuvant treatment & 2 & 1 & 2 \\
Very Low Tumor $(<5 \mathrm{~cm}$ & & & \\
from anal verge) & & & \\
\hline
\end{tabular}

morbidities, compared to 1.0 and 3.0 in the $\mathrm{OW}$ and $\mathrm{OB}$ groups. The median ASA scores were 2.0, 2.0, and 3.0 respectively.

Very low rectal tumors were defined as those that are less than $5 \mathrm{~cm}$ from the anal verge. Distance from the lower edge of the tumor to the anal verge was recorded for the patients. A total of five patients had very low tumors $(\mathrm{NW}=2 ; \mathrm{OW}=1 ; \mathrm{OB}=2)$.

\section{Perioperative outcomes}

The median operative times for the NW, OW and OB groups were 195.0 minutes; 240.5 minutes and 264.0 minutes, respectively. There were no significant differences among the groups with respect to length of stay or blood loss (Table 3). The rates of conversion to open procedure were comparable for the NW and OW groups at $14.3 \%$ and $16.7 \%$, respectively, while the OB group

Table 3 Outcomes

\begin{tabular}{|c|c|c|c|}
\hline \multirow[t]{2}{*}{ Parameter } & Normal weight & Overweight & Obese \\
\hline & $N=7$ & $N=12$ & $N=7$ \\
\hline Median LOS (days) & 12.0 & 7.0 & 5.0 \\
\hline Range & 4.0 to 30.0 & 3.0 to 14.0 & 4.0 to 17.0 \\
\hline $\begin{array}{l}\text { Median estimated blood } \\
\text { loss }(\mathrm{ml})\end{array}$ & 200.0 & 200.0 & 200.0 \\
\hline Range & 50.0 to 700.0 & 50.0 to 650.0 & 125.0 to 500.0 \\
\hline $\begin{array}{l}\text { Median operative } \\
\text { time (minutes) }\end{array}$ & 195.0 & 240.5 & 264.0 \\
\hline Range & 125.0 to 351.0 & 127.0 to 578.0 & 143.0 to 359.0 \\
\hline $\begin{array}{l}\text { Median number of lymph } \\
\text { nodes retrieved }\end{array}$ & 19.0 & 20.0 & 19.0 \\
\hline Range & 9.0 to 32.0 & 9.0 to 46.0 & 15.0 to 31.0 \\
\hline $\begin{array}{l}\text { Median lymph node ratio } \\
\text { (positive/total) }\end{array}$ & 0.32 & 0.13 & 0.00 \\
\hline Range & 0.00 to 0.72 & 0.00 to 0.61 & 0.00 to 0.83 \\
\hline Negative margins (radial) & $7(100 \%)$ & $10(83.3 \%)$ & $6(85.7 \%)$ \\
\hline $\begin{array}{l}\text { Negative margins } \\
\text { (proximal/distal) }\end{array}$ & $7([100 \%)$ & $12(100 \%)$ & 7 (100\%) \\
\hline Conversion & $1(14.3 \%)$ & $2(16.7 \%)$ & $0(0 \%)$ \\
\hline $\begin{array}{l}\text { No. of patients } \\
\text { with complications }\end{array}$ & $2(28.3 \%)$ & $4(33.3 \%)$ & $1(14.3 \%)$ \\
\hline Mortality & - & 1 & - \\
\hline
\end{tabular}

had no conversions. Major and minor complications occurred in $28.3 \%$ of NW, $33.3 \%$ of OW and $14.3 \%$ of OB (Tables 3 and 4). For the purpose of standardization, the complications were also graded using the Clavien Score. The only mortality in the series was recorded in the OW group as a result of postoperative massive pulmonary embolism in a patient who underwent laparoscopic abdominoperineal resection for T3 rectal cancer. This patient had neoadjuvant chemoradiation therapy.

\section{Oncologic parameters}

The three groups were compared for lymph node retrieval on pathologic examination of resected specimens, as well as proximal, distal and radial margins. The median lymph node harvest was 19.0 for the NW group, 20.0 for the OW group, and 19.0 for the OB group. Median node ratios for $\mathrm{NW}, \mathrm{OW}$ and $\mathrm{OB}$ were $0.32,0.13$ and 0.00 , respectively. All patients in the study had negative proximal and distal bowel margins. Radial margin negativity rates were $100 \%, 83.3 \%$ and $85.7 \%$ for NW, OW and $\mathrm{OB}$, respectively.

\section{Discussion}

There is a paucity of data on the relationship between obesity and outcomes of totally laparoscopic resections for rectal cancer (TLRR). Bege et al. were the first to compare outcomes of laparoscopic rectal resection for cancer between obese and non-obese patients. They reported increased conversion rate and operative time for obese patients but the overall morbidity was comparable for both groups [1]. The bulk of data on the impact of obesity on colorectal surgery is predominantly from colonic resections. Results have been conflicting, with Delaney et al. reporting no difference in operative time, complication rate or cost [2] while other groups reported significant differences in those parameters $[3,4]$.

Table 4 Complications

\begin{tabular}{|c|c|c|c|c|}
\hline Complication & $\begin{array}{l}\text { Clavien } \\
\text { Score }\end{array}$ & $\begin{array}{l}\text { Normal weight } \\
(n=7)\end{array}$ & $\frac{\text { Overweight }}{(n=12)}$ & $\frac{\text { Obese }}{(n=7)}$ \\
\hline Sacral decubitus ulcer & Grade I & 1 & - & - \\
\hline Acute renal failure & Grade I & 1 & - & - \\
\hline Surgical site infection & Grade I & 1 & - & 2 \\
\hline lleus & Grade I & 1 & - & 1 \\
\hline Pulmonary embolism & Grade II & 1 & 1 & - \\
\hline Pneumonia & Grade II & 2 & - & - \\
\hline UTI & Grade II & 1 & 1 & - \\
\hline Pelvic abscess & Grade IIla & 2 & - & - \\
\hline Anastomotic leak & Grade IIIb & 1 & - & - \\
\hline $\begin{array}{l}\text { Bleeding requiring } \\
\text { reoperation }\end{array}$ & Grade IIIb & 1 & - & - \\
\hline
\end{tabular}


Laparoscopic rectal resection for malignancy is technically more demanding. This may at least partly explain the limited availability of this procedure and lack of relevant data. Concerns about nerve preservation, complete total mesorectal excision, and adequate lymph node harvest are still unanswered in this setting.

In view of the peculiar technical challenges of laparoscopic rectal cancer surgery, it would be inappropriate to simply extrapolate the data from laparoscopic colonic resections [1]. The CLASSIC trials by Guillou et al. in 2005 and 2007 are Level 1 studies that addressed shortterm and long-term outcomes of laparoscopic assisted colorectal cancer surgery $[5,6]$.

TLRR is evolving. This unique study specifically addresses a TLRR with emphasis on locally-advanced disease defined as T3/T4. Additionally, the role of varying levels of obesity is examined. Besides the association between obesity and occurrence of colorectal cancer [8], the safety, feasibility, short-term outcomes and oncologic effectiveness of this approach could be affected by obesity. This was examined in the present study. Median age, gender distribution, cancer location, tumor stage, medical comorbidities, ASA score, lymph node harvest and margin positivity rates were comparable for the three BMI groups studied.

The presence of lymph node metastasis is important for predicting the clinical outcome of patients who have undergone radical surgery for colorectal carcinoma and for making decision on need for adjuvant therapy. Therefore, an accurate measurement of the pathologic status of the tumor lymph nodes in the specimen is important for reducing the risk of understaging [9]. This study showed no difference in the median number of lymph nodes harvested in each of the three weight groups $(\mathrm{NW}=19.0$, range 9.0 to 32.0 ; $\mathrm{OW}=20.0$, range 9.0 to $46.0 ; \mathrm{OB}=19.0$, range 15.0 to 31.0$)$. Median node ratios for $\mathrm{NW}$, $\mathrm{OW}$ and $\mathrm{OB}(0.32$, range 0.00 to 0.72 ; 0.13 , range 0.00 to 0.61 and 0.00 , range 0.00 to 0.83 respectively) also did not show any significant difference. Although the AJCC and IUAC guidelines [10] suggest $>12$ lymph nodes as an adequate harvest for colon cancer, it is unclear whether these node thresholds should apply to rectal cancer especially for patients who had neoadjuvant treatment. Nonetheless, in the present study of the laparoscopic technique, the average nodal harvest was well in excess of these recommendations. However, Gorog et al. reported a finding of significantly lower number of retrieved lymph nodes from rectal resection specimens in patients with BMI $>/=25 \mathrm{~kg} / \mathrm{m}^{2}$ compared to those with $\mathrm{BMI}<25 \mathrm{~kg} / \mathrm{m}^{2}$ when the length of the resected specimen was less than $16 \mathrm{~cm}$ [11]. These findings indicate that the quantity and adequacy of mesorectal lymph node dissection for rectal cancer has not been firmly established.
Negative proximal/distal margin rates were $100 \%$ for the NW, OW and OB groups. Negative radial margin rates were $100 \%, 83.3 \%$ and $85.7 \%$ for the NW, OW and $\mathrm{OB}$ groups respectively. The two patients in the OW group with positive radial margin presented with obstructing tumors which required prompt surgical intervention that made it impossible for them to undergo neoadjuvant chemoradiation. Both were extraluminal, invasive rectal tumors with adherence to surrounding structures. The only patient in the OB group with positive radial margin presented with bleeding rectal tumor necessitating prompt surgery, which also prevented administration of neoadjuvant chemoradiation.

Operative time increased slightly with progression from non-obese to obese patients, but was not significant. The small numbers in this study certainly do not contradict the findings from other studies that have documented longer duration of surgery for obese patients [1]. Median blood loss was similar for the three groups, standing at $200 \mathrm{ml}$.

The rate of complications for the OB group (14.3\%) is almost half of that for NW (28.6\%) and OW (33.3\%)-an unusual observation. This may be explained by the fact that none of the patients in the $\mathrm{OB}$ group underwent neoadjuvant chemoradiotherapy compared to $57.1 \%$ of NW and $16.7 \%$ of OW. This observation is congruent with earlier studies which have associated neodjuvant chemoradiation with greater technical difficulty and increased perineal wound complications in laparoscopic rectal cancer resection [12]. For ease of universal reference and standardization of documentation, each complication was graded using the Clavien Score.

The overall conversion rate in this series of locallyadvanced rectal cancers (T3/T4) is $11.5 \%$. Conversion rate for laparoscopic rectal cancer resection is documented in the Conventional versus Laparoscopic-Assisted Surgery in Colorectal Cancer [CLASICC] trial to be $34 \%$. More recently it has been documented in the literature as ranging from 2.8 to $9.8 \%$ [13-16], for all Tstages combined. The authors' experience with lower conversion rates in locally advanced tumors likely reflects the continual refinement that laparoscopic rectal surgery has undergone since the CLASICC trial, in addition to careful patient selection.

In this study, the NW group had a longer median length of hospital stay than the OW and OB groups. The presence of an outlier in the NW group with length of stay of 30 days is noted. The postoperative course in this patient was complicated by prolonged ileus initially, followed by rapid atrial fibrillation, fungemia, pneumonia and superficial wound infection.

Over the years concerns have arisen regarding the results of laparoscopic rectal cancer resection compared with open conventional resection. Many studies have 
documented longer operative time for laparoscopic rectal cancer resection compared to the open approach. However, this shortcoming is often offset by shorter hospital stays, earlier return of bowel function, decreased blood loss and better preservation of autonomic nerves $[17,18]$. In terms of five-year local and distant recurrence rates, five-year overall survival and disease-free survival, results are comparable, without the benefit of large series $[14-16,19,20]$.

\section{Conclusion}

The present series adds to the body of literature supporting the feasibility and safety of the totally laparoscopic technique in treating obese patients with locally advanced (T3/T4) rectal cancers which could also be confirmed with further studies. Both perioperative outcomes and surrogates of oncologic surgical quality from TLRR are comparable to the reported results for non-obese patients in the current literature. While this study is limited by a modest cohort, the data support that totally laparoscopic rectal resection may be an appropriate and safe technique applicable to obese patients.

\section{Abbreviations}

BMI: Body mass index; IMA: Inferior mesenteric artery; NS: Not significant; NW: Normal weight; OW: Overweight; OB: Obese; TLRR: Totally-laparoscopic rectal cancer resection.

\section{Competing interests}

There are no competing interests and we have not received any grants or financial support for this study.

\section{Acknowledgements}

The efforts of Tassos Kyriakides Ph D in statistical analysis of data were greatly appreciated and are hereby acknowledged.

\section{Author details}

'Division of Surgical Oncology, Department of Surgery, Roger Williams Medical Center, Boston University, Prior 4, 825 Chalkstone Avenue, Providence, RI 02908, USA. ${ }^{2}$ Department of Surgery Hospital of Saint Raphael, Affiliate of Yale School of Medicine, 1450 Chapel Street, New Haven, CT 06511, USA.

\section{Authors' contributions}

TO, KB, SK, JE and PS made substantial contributions to the concept and design of the research, data acquisition and analysis, manuscript drafting and revision, as well as final approval for publication. All authors read and approved the final manuscript.

Received: 25 January 2012 Accepted: 16 July 2012

Published: 16 July 2012

\section{References}

1. Bège T, Lelong B, Francon D, Turrini O, Guiramand J, Delpero JR: Impact of obesity on short-term results of laparoscopic rectal cancer resection. Surg Endosc 2009, 23:1460-1464.

2. Delaney CP, Pokala N, Senagore AJ, Casillas S, Kiran RP, Brady KM, Fazio WW Is laparoscopic colectomy applicable to patients with body mass index $>30$ ? A case-matched comparative study with open colectomy. Dis Colon Rectum 2005, 48:975-981.

3. Pikarsky AJ, Saida Y, Yamaguchi T, Martinez S, Chen W, Weiss EG, Nogueras $\mathrm{JJ}$, Wexner SD: Is obesity a high-risk factor for laparoscopic colorectal surgery? Surg Endosc 2002, 16:855-858.
4. Schwandner O, Farke S, Schiedeck TH, Bruch HP: Laparoscopic colorectal surgery in obese and nonobese patients: do differences in body mass indices lead to different outcomes? Surg Endosc 2004, 18:1452-1456.

5. Guillou PJ, Quirke P, Thorpe H, Walker J, Jayne DG, Smith AM, Heath RM, Brown JM, MRC CLASICC trial group: Short-term endpoints of conventional versus laparoscopic-assisted surgery in patients with colorectal cancer (MRC CLASICC trial): multicentre randomised controlled trial. Lancet 2005, 365:1718-1726.

6. Jayne DG, Guillou PJ, Thorpe H, Quirke P, Copeland J, Smith AM, Heath RM, Brown JM, UK MRC CLASICC Trial Group:: Randomized trial of laparoscopic-assisted resection of colorectal carcinoma: 3-year results of the UK MRC CLASICC Trial Group. J Clin Oncol 2007, 25:3061-3068.

7. Karahasanoglu T, Hamzaoglu I, Baca B, Aytac E, Kirbiyik E: Impact of increased body mass index on laparoscopic surgery for rectal cancer. Eur Surg Res 2011, 46:87-93.

8. Calle EE, Rodriguez C, Walker-Thurmond K, Thun MJ: Overweight, obesity, and mortality from cancer in a prospectively studied cohort of U.S. adults. N Engl J Med 2003, 348:1625-1638.

9. Cianchi F, Palomba A, Boddi V, Messerini L, Pucciani F, Perigli G, Bechi P, Cortesini C: Lymph node recovery from colorectal tumor specimens: recommendation for a minimum number of lymph nodes to be examined. World J Surg 2002, 26:384-389.

10. Hernanz F, Revuelta S, Redondo C, Madrazo C, Castillo J, Gómez-Fleitas M: Colorectal adenocarcinoma: quality of the assessment of lymph node metastases. Dis Colon Rectum 1994, 37:373-377.

11. Görög D, Nagy P, Péter A, Perner F: Influence of obesity on lymph node recovery from rectal resection specimens. Pathol Oncol Res 2003, 9:180-183.

12. EnLeroy J, Jamali F, Forbes L, Smith M, Rubino F, Mutter D, Marescaux J: Laparoscopic total mesorectal excision (TME) for rectal cancer surgery: long-term outcomes. Surg Endosc 2004, 18:281-289.

13. Ng SSM, Leung KL, Lee JFY, Yiu RYC, Li JCM, Teoh AYB, Leung WW: Laparoscopic-assisted versus open abdominoperineal resection for low rectal cancer: a prospective randomized trial. Ann Surg Oncol 2008, $15: 2418-2425$

14. Ng KH, Ng DC, Cheung HY, Yau KK, Chung CC, Li MK: Laparoscopic resection for rectal cancers: lessons learned from 579 cases. Ann Surg 2009, 249:82-86

15. Liang JT, Huang KC, Lai HS, Lee PH, Jeng YM: Oncologic results of laparoscopic versus conventional open surgery for stage II or III leftsided colon cancers: a randomized controlled trial. Ann Surg Oncol 2007, 14:109-117.

16. Veenhof AA, der Peet DL E, Sietses C, Meijerink WJ, de Lange-de Klerk ES, Cuesta MA: Technical difficulty grade score for the laparoscopic approach of rectal cancer: a single institution pilot study. Int I Colorectal Dis 2008, 23:469-475.

17. Braga M, Frasson M, Vignali A, Zuliani W, Capretti G, Di Carlo V: Laparoscopic resection in rectal cancer patients: outcome and costbenefit analysis. Dis Colon Rectum 2007, 50:464-471.

18. Zhou ZG, Hu M, Li Y, Lei WZ, Yu YY, Cheng Z, Li L, Shu Y, Wang TC: Laparoscopic versus open total mesorectal excision with anal sphincter preservation for low rectal cancer. Surg Endosc 2004, 18:1211-1215.

19. Bretagnol F, Lelong B, Laurent C, Moutardier V, Rullier A, Monges G, Delpero $J R$, Rullier $E:$ The oncological safety of laparoscopic total mesorectal excision with sphincter preservation for rectal carcinoma. Surg Endosc 2005, 19:826-896.

20. Feliciotti F, Guerrieri M, Paganini AM, De Sanctis A, Campagnacci R, Perretta S, D'Ambrosio G, Lezoche E: Long-term results of laparoscopic versus open resections for rectal cancer for 124 unselected patients. Surg Endosc 2003, 17:1530-1535.

doi:10.1186/1477-7819-10-147

Cite this article as: Oyasiji et al.: Feasibility of purely laparoscopic resection of locally advanced rectal cancer in obese patients. World Journal of Surgical Oncology 2012 10:147. 